\title{
General situation of the stereological studies in Turkey
}

\author{
Selda Kahvecia ${ }^{a}$ Ayşe Menekşe Kırbaşoğlu ${ }^{a^{*}}$, Meltem Dedeoğlu ${ }^{\text {a }}$, Perihan Aşcı ${ }^{\text {a }}$ Merve Katrancı ${ }^{\text {b }}$ \\ ${ }^{a}$ Department of Histology and Embriyology, University of Adnan Menderes, Aydin, Turkey \\ ${ }^{b}$ Department of Bioistatistic, University of Adnan Menderes, Aydin, Turkey
}

\section{ARTICLE INFO}

\section{* Correspondence to:}

Ayşe Menekşe Kırbaşoğlu

Department of Histology and Embriyology, Faculty of Medicine,

University of Adnan Menderes, Aydın, Turkey

e-mail: ayşe.mk@hotmail.com

\section{Keywords:}

Histology

Investigation

Stereology

Turkey

\section{ABSTRACT}

Stereological studies that have been made in Turkey by analyzing the statistical data to obtain different categories. To scientific researchs conducted at Turkey of Stereology field has been reached from www.pubmed.com ,www.ulakbim.com, High Education Board thesis search page and University of Adnan Menderes library.The data obtained have been classed four categories on the brink of according to the university, to year, to the department and by subject.And afterwards, the statistical results belonging to each categories have been received. In this study, it has been studied mostly in the field of hippocampus according to the subjects and most of the publications belong to the department of Histology and Embryology. As for the years, mostly in 2011, studies in this field were done at Ondokuz Mayis University.

J. Exp.Clin.Med., 2014; 31:129 